\title{
SOIL CREEP IN BALEKAMBANG, CIRAWAMEKAR, CIPATAT DISTRICT, BANDUNG BARAT REGENCY, WEST JAVA
}

\author{
RAYAPAN TANAH DI BALEKAMBANG, CIRAWAMEKAR, \\ KECAMATAN CIPATAT, KABUPATEN BANDUNG BARAT, JAWA \\ BARAT
}

\author{
Iwan G Tejakusuma ${ }^{1}$
}

\begin{abstract}
Soil creep occurred in Balekambang, Cirawamekar, Cipatat, West Bandung Regency, West Java. This area is karst hill consist of limestone with interbedded sediment in the valley. The limestone is interfingered with clay, marl and quartz sandstones. The clay and marl acting as the slipping plane with a steep dip of around $50^{\circ}$ to $69^{\circ}$ to the northwest. The direction of the slope movement approximately follows the direction of the bedding plane therefore the bedding plane control the soil creep. This landslide was triggered by rainfall which saturated the soil layer and environmental change in the surrounding area.
\end{abstract}

Keywords: soil creep, slip plane, environmental change, rainfall

\begin{abstract}
Abstrak
Soil creep atau rayapan tanah terjadi di Balekambang, Cirawamekar, Cipatat, Kabupaten Bandung Barat, Jawa Barat. Daerah ini merupakan perbukitan karst yang terdiri dari batugamping dengan lembahnya berupa batuan sedimen berlapis. Batugamping ini menjari dengan lempung, napal dan batupasir kuarsa. Lempung dan napal diduga merupakan batuan yang berfungsi sebagai bidang gelincir dengan kemiringan dip cukup curam sekitar $50^{\circ}$ hingga $69^{\circ}$ ke arah barat laut. Arah gerakan tanah mengikuti arah perlapisan mencirikan peran struktur perlapisan yang mengontrol terjadinya longsor. Longsor ini dipicu oleh curah hujan yang menjenuhkan tanah dan perubahan lingkungan di sekitar daerah Balekambang.
\end{abstract}

Kata kunci: rayapan tanah, bidang gelincir, perubahan lingkungan,curah hujan

1 Pusat Teknologi Reduksi Risiko Bencana - Badan Pengkajian dan Penerapan Teknologi, Jl. M. H. Thamrin No.8, Jakarta 10340, email: iwan.tejakusuma@gmail.com

\section{PENDAHULUAN}

Gerakan tanah atau yang di masyarakat lebih dikenal sebagai longsor merupakan fenomena yang terjadi di wilayah Indonesia. Kondisi geologi, dan curah hujan tropis yang tinggi, perubahan iklim serta aktivitas manusia yang merubah lingkungan kerap berinteraksi dalam terjadinya longsor di Indonesia. Perubahan lingkungan diduga menjadi faktor yang semakin penting dalam terjadinya bencana gerakan tanah pada beberapa tahun terakhir.

Dalam mitigasi bencana gerakan tanah, selain pembuatan peta zona kerentanan gerakan tanah yang telah dilakukan oleh PVMBG, Badan
Geologi Kementerian Energi Dan Sumber Daya Mineral (http://vsi.esdm.go.id/gallery/index. php?/category/12), diperlukan pula kajian yang lebih detail pada lokasi dengan risiko bencana gerakan tanah yang tinggi. Banyak daerahdaerah di Indonesia yang telah dihuni ternyata berada pada wilayah zona kerentanan gerakan tanah sedang hingga tinggi.

Pemahaman terhadap proses atau mekanisme terjadinya gerakan tanah menjadi bagian yang penting dalam melakukan upaya mitigasi bencana. Dalam penelitian tahap awal, identifikasi potensi bahaya gerakan tanah kemudian pengetahuan tentang kondisi gerakan tanah hingga prediksi mekanisme terjadinya 
gerakan tanah diperlukan dalam mitigasi pengurangan risiko bencana gerakan tanah.

Menurut Petley (2012) dalam pola global bencana longsor yang memakan korban jiwa, terlihat bahwa kejadian bencana longsor terbanyak terdapat di Asia, Longsor yang terjadi ternyata berkaitan dengan siklus tahunan. Implikasinya adalah pada manajemen bencana longsor dimana terdapat dua hal penting yaitu perlunya peningkatan penelitian tentang longsor khususnya proses terjadinya longsor, ambang batas longsor, mekanisme longsor dan mitigasi bencana longsor di Asia khususnya di Indonesia serta kuantifikasi kecenderungan bencana longsor yang akan terjadi sebagai akibat dari perubahan iklim (Petley, 2012).

Berbagai faktor berpengaruh dan berinteraksi dalam terjadinya bencana longsor yang memerlukan keahlian, pengalaman dan riset yang kontinyu dalam memahami bencana longsor. Chen dan Huang (2013) menunjukkan bahwa perubahan tutupan vegetasi juga telah menyebabkan perubahan daerah yang terkena longsor demikian pula frekuensinya. Daerah yang mengalami perubahan penggunaan lahan merupakan daerah yang kerap dilanda longsor dibandingkan dengan daerah yang tidak mengalami perubahan penggunaan lahan (Chen dan Huang, 2013). Hadmoko et al (2010) juga menyatakan pentingnya pengkajian bahaya dan risiko longsor untuk pencegahan risiko dan perencanaan tata ruang sebagai contoh studinya di Perbukitan Menoreh.

Longsor yang memakan korban jiwa yang besar di Indonesia terjadi khususnya di Pulau Jawa dan risiko bencana longsor tertinggi diketahui terdapat di Provinsi Jawa Barat. Di Provinsi Jawa Barat yaitu di daerah Kabupaten Bandung Barat dan sekitarnya memiliki potensi bencana gerakan tanah yang sedang hingga tinggi yang cukup luas, hal ini dikarenakan morfologinya banyak merupakan perbukitan bergelombang, perbukitan batugamping dan bahkan terdapat morfologi gunung yaitu sebagian Gunung Malabar dan Gunung Tangkuban Perahu. Gerakan tanah berbagai tipe dapat ditemukan di wilayah ini. Salah satu longsor yang terjadi dapat ditemukan di daerah Kecamatan Cipatat, Desa Cirawamekar, di Kampung Balekambang.

Untuk mengetahui secara langsung kondisi gerakan tanah maka dilakukan studi di daerah lokasi dan hasilnya diterangkan pada tulisan ini dan diuraikan pada bagian berikut ini. Dengan mengetahui kondisi gerakan tanah maka diharapkan bencana gerakan tanah di daerah ini dapat diminimalisir.

\section{METODE PENELITIAN}

Kajian tentang longsor di Balekambang, Desa Cirawamekar di Kecamatan Cipatat, Kabupaten Bandung Barat ini dilakukan melalui beberapa metode. Metode yang dilakukan dan tahapannya adalah sebagai berikut:

- Studi literatur serta studi pustaka baik data, informasi dari penelitian sebelumnya yang telah dilakukan khususnya mencakup kondisi geografi, kondisi geologi, kondisi longsor dan kejadian longsor.

- Melakukan penelitian lapangan mencakup survei kondisi longsor, topografi, geomorfologi dan kondisi lereng.

- Melakukan pengamatan dan deskripsi kondisi bencana longsor atau gejala longsor yang terjadi di lapangan khususnya dari aspek geologi dan lingkungan serta aspek lain yang mungkin berpengaruh besar untuk terjadinya longsor.

- Melakukan wawancara dengan penduduk setempat tentang longsor dan kondisi sekitarnya.

- Melakukan analisis kejadian longsor serta membuat prediksi mekanisme terjadinya longsor.

\section{HASIL DAN PEMBAHASAN}

\subsection{Geografi Daerah Kabupaten Bandung Barat}

Berdasarkan data yang didapat dari http://bandungbaratkab.go.id/halaman/geografis$\mathrm{kbb}$, diketahui bahwa luas wilayah Kabupaten Bandung Barat adalah 1.305,77 km², terletak antara $06^{\circ} 41^{\prime}$ sampai dengan $07^{\circ} 19^{\prime}$ Lintang Selatan dan $107^{\circ} 22^{\prime}$ sampai dengan $108^{\circ} 05^{\prime}$ Bujur Timur. Ketinggian rata-rata wilayah Kabupaten Bandung Barat adalah 110 meter dan maksimum 2.243 meter dari permukaan laut. Kemiringan wilayah bervariasi antara $0-8 \%, 8-$ $15 \%$ hingga diatas $45 \%$, dengan batas wilayah di sebelah barat Kabupaten Cianjur, sebelah utara Kabupaten Purwakarta dan Kabupaten Subang, sebelah Timur dengan Kabupaten Bandung, Kota Bandung, dan Kota Cimahi sedangkan di selatan berbatasan dengan Kabupaten Bandung dan Kabupaten Cianjur. Penggunaan Iahan di wilayah Kabupaten Bandung Barat, merupakan budidaya pertanian sebagai penggunaan lahan terbesar yaitu 66.500,294 hektar, sedangkan yang termasuk kawasan lindung seluas 50.150,928 hektar, budidaya non pertanian seluas $12.159,151$ hektar dan lainnya seluas 1.768,654 hektar.

Kawasan lindung di daerah Kabupaten Bandung Barat terkait dengan isu kawasan bandung utara sebagai daerah resapan air bagi cekungan Bandung. Daerah wilayah Kabupaten Bandung Barat dinilai kurang menguntungkan, karena terdiri dari banyak cekungan yang berbukit-bukit dan di daerah-daerah tertentu sangat rawan dengan bencana alam (http://bandungbaratkab.go.id/ halaman/ geografis$\mathrm{kbb})$. 


\section{Geologi Daerah Longsor Balekambang}

Berdasarkan peta geologi Lembar Cianjur (Sudjatmiko, 1972), daerah Kampung Balekambang dan sekitarnya, tersusun oleh endapan laut dangkal dari Formasi Rajamandala. Formasi Rajamandala ini tersusun secara jari jemari antara batugamping dengan lempung, napal dan batupasir kuarsa (gambar 1).

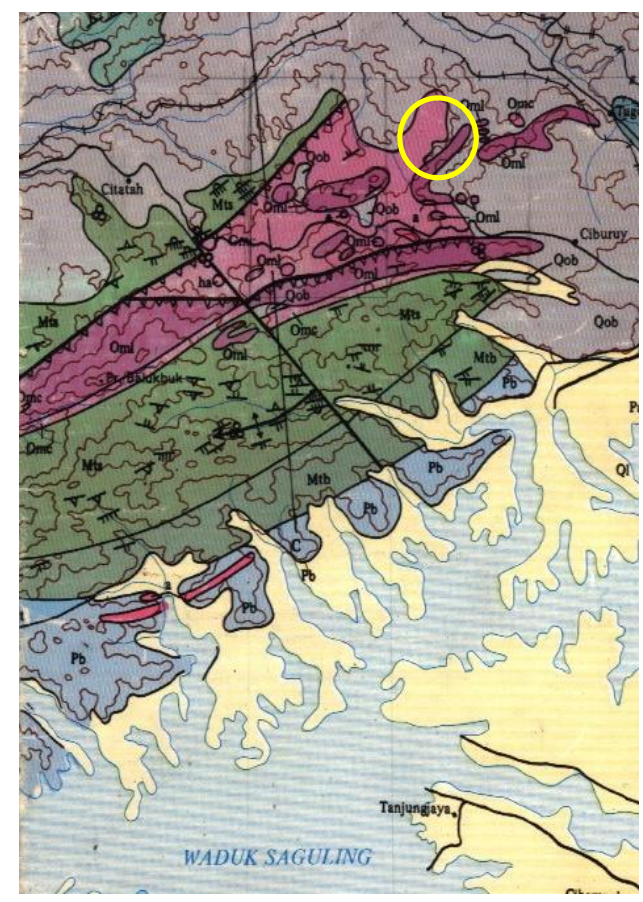

Gambar 1. Geologi Daerah Kampung Balekambang yang mengalami longsor, di Desa Cirawamekar, Kecamatan Cipatat, Kabupaten Bandung Barat (dalam lingkaran), diambil dari Sudjatmiko (1972). Daerah ini tersusun oleh batuan dari Formasi Rajamandala.

Berdasarkan pengamatan lapangan, morfologi batugamping ini menunjukkan morfologi yang kontras berbeda dengan batuan sekelilingnya dengan bukit batugamping yang menjulang dengan kemiringan lereng yang curam. Batugamping ini ditambang untuk keperluan bahan bangunan. Pada daerah dekat Kampung Balekambang, batugamping ini terlihat masih ditambang dengan menggunakan alat berat. Penambangan ini meningkatkan potensi longsor batuan bila tidak dilakukan penambangan dengan benar. Selain itu kondisi hidrogeologi yang ada juga dapat berubah akibat penambangan ini dimana dapat mengakibatkan air tanah menjadi terganggu dan sulit didapat dibandingkan dengan sebelum ditambang.

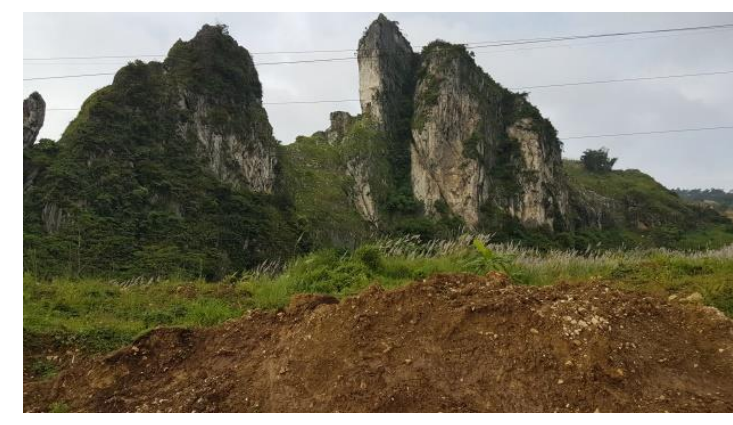

Gambar 2. Kontras morfologi batugamping berlereng curam dengan batuan sekitarnya yang tersusun oleh batuan lempung, napal dan batupasir kuarsa. Lokasi menuju Kampung Balekambang.

Berdasarkan peta geologi Lembar Cianjur tersebut (Sudjatmiko, 1972) batuan lempung, napal dan batupasir kuarsa memiliki perlapisan dengan kemiringan atau dip yang cukup curam yaitu antara 500 hingga 690 ke arah barat laut dengan arah perlapisan atau strike relatif timur laut - barat daya. Daerah yang longsor di Kampung Balekambang ini berada pada batuan tersebut dimana lapisan batulempung atau napal dapat berfungsi sebagai bidang gelincir longsor.

\section{Kejadian Longsor Di Balekambang Kecamatan Citatah}

Berdasarkan data PVMBG (2016) gerakan tanah terjadi di RT 02 dan RT 04, RW 10, Kampung Balekambang, Desa Cirawamekar, Kecamatan Cipatat, Kabupaten Bandung Barat, Provinsi Jawa Barat. Lokasi gerakan tanah secara geografi terletak pada koordinat $006^{\circ} 49^{\prime} 06,2^{\prime \prime}$ Lintang Selatan dan $107^{\circ} 26^{\prime}$ 56,8' Bujur Timur. Gerakan tanah di daerah ini terjadi pada hari Jumat, 18 November 2016 malam. Jenis gerakan tanah adalah rayapan dan sebagai akibat gerakan tanah tersebut muncul retakan pada permukaan tanah serta bangunan yang berada di areal gerakan tanah arah umum Barat - Timur. Gerakan tanah mempunyai arah umum N $272^{\circ} \mathrm{E}$, panjang 200, lebar 150 meter. Dampak gerakan tanah adalah 5 (lima) rumah rusak berat, 20 (dua puluh) rumah rusak sedang, 26 kepala keluarga yang terdiri dari 86 jiwa mengungsi dan jalan desa rusak (PVMBG, 2016).

\section{Pengamatan Lapangan Longsor Balekambang}

Berdasarkan survei lapangan dan wawancara dengan penduduk setempat yang dilakukan pada bulan April 2018 didapatkan beberapa data dan informasi tentang longsor Balekambang. Longsor terjadi di daerah Kompleks Madrasah Aliyah Miftahul Ulum. Di dalam kompleks ini terdapat rumah, asrama, masjid dan fasilitas umum. Di 
daerah ini yaitu didekat jalan utama sebelah utara asrama terdapat mata air dengan debit yang cukup besar. Mata air ini sangat menguntungkan karena dapat dipergunakan untuk keperluan sehari hari kegiatan di madrasah dan sekitarnya. Di sebelah barat laut kompleks terdapat persawahan dan kemudian ladang. Mata air ini kemungkinan muncul pada batas antara batugamping dan lempung serta napal.

Longsor di daerah ini berjalan secara lambat dan pergerakannya tidak menerus, namun bergerak pada waktu tertentu dan kemudian berhenti. Pergerakan ini dapat berulang pada periode waktu tertentu. Berdasarkan pengamatan maka diduga pergerakan ini kemungkinan dipicu oleh curah hujan yang tinggi yang mengakibatkan meningkatnya massa tanah yang jenuh air di daerah Balekambang. Pembebanan akibat adanya bangunan rumah dan fasilitas lainnya menambah tekanan pada permukaan tanah. Oleh karena itu untuk mengurangi risiko berulangnya gerakan tanah disarankan agar penambahan bangunan berada di luar kompleks madrasah. Selain itu perubahan lingkungan khususnya perubahan lahan hutan yang berubah menjadi semak dan permukiman serta pertambangan batugamping dapat berkontribusi dalam terjadinya gerakan tanah. Tanaman dapat berfungsi sebagai penahan curah hujan agar tidak langsung menyerap ke dalam tanah. Tanaman juga dapat menyerap air dan menguapkannya kembali dalam proses evapotranspirasi sehingga jumlah air yang menyerap ke dalam tanah secara berlebihan dapat dikurangi.

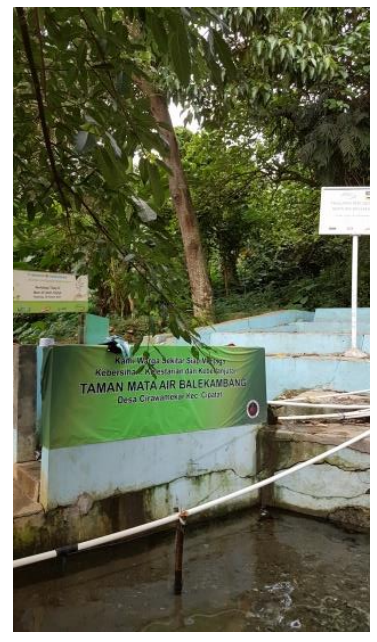

Gambar 3. Mata air dengan debit yang cukup besar di kompleks madrasah di Balekambang.

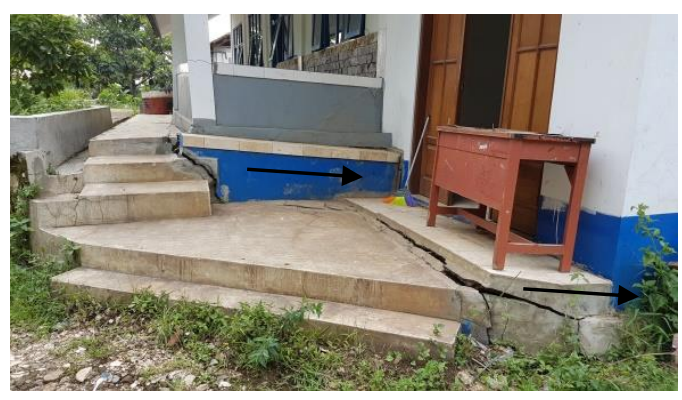

Gambar 4. Rekahan bangunan di kompleks madrasah di Balekambang. Tanda panah menunjukkan arah gerakan yaitu kea rah barat laut.

Perubahan iklim yang berakibat pada berubahnya pola hujan dapat juga menjadi salah satu faktor yang menyebabkan gerakan tanah. Pola hujan dengan intensitas yang sangat tinggi dan dalam waktu yang relatif singkat dapat menyebabkan tanah menjadi jenuh dengan cepat dan merubah kestabilan lereng.

\section{Jenis Longsor Balekambang}

Jenis longsor di Balekambang dapat diklasifikasikan berdasarkan Varnes (1978) yang membagi beberapa jenis longsor berdasarkan jenis material longsor dan tipe pergerakannya. Berdasarkan klasifikasi Varnes (1978) ini, longsor Balekambang adalah termasuk jenis longsor yang disebut dengan soil creep. Berdasarkan Hungr et al (2014) yang memperbarui klasifikasi Varnes (1978) jenis longsor yang terjadi adalah juga jenis soil creep. Longsor jenis soil creep ini pergerakannya lambat. Pergerakan yang lambat ini dan tidak menerus namun bergerak dalam waktu tertentu saja menunjukkan bahwa lereng sebetulnya dalam kondisi stabil. Namun tingkat kestabilannya mendekati tingkat tidak stabil. Pergerakan kondisi lereng dari stabil ke tidak stabil menunjukkan bahwa ada yang memicu untuk reaktivasi.

Soil creep diperkirakan dikontrol oleh kondisi geologi yaitu adanya lempung dan napal di lapisan di bawah permukaan yang bersifat kedap air. Arah perlapisan batuan kedap air lebih kurang serupa dengan arah kemiringan lereng sehingga kondisi ini membuat batulempung dapat berfungsi sebagai bidang gelincir longsor.

\subsection{Pembahasan Soil Creep}

Selain di Balekambang, rayapan tanah atau soil creep juga terjadi di beberapa tempat di Jawa Barat seperti di Desa Jahiyang, Salawu, Kabupaten Tasikmalaya. Sarah dan Daryono (2012) yang meneliti daerah tersebut menyatakan bahwa kestabilan lereng di daerah tersebut sangat dipengaruhi oleh peningkatan permukaan air tanah yang ditandai dengan penurunan faktor keamanan dan peningkatan pergerakan lereng. Sadarviana et al (2010) 
meneliti gerakan tanah di Ciloto, Jawa Barat dan menunjukkan bahwa gerakan tanah di daerah ini termasuk jenis gerakan tanah yang sangat lambat, dengan kecepatan $5 \times 10^{-5}$ hingga $5 \times 10^{-}$ $7 \mathrm{~mm} /$ detik. Sabir et al (2016) melakukan studi kecepatan soil creep di Pakistan dan menemukan bahwa dalam satu lereng yang sama, kecepatan gerakan tanah pada bagian bagian lereng dapat berbeda. Selain itu diketahui juga bahwa umur pohon memiliki efek terbailk terhadap kecepatan soil creep, sedangkan tinggi pohon memiliki efek yang sangat kecil atau tidak ada efek sama sekali terhadap kecepatan soil creep.

Kusumayudha dan Ciptahening (2016) membahas tentang korelasi antara lingkungan tektonik dan gerakan tanah untuk studi kasus Pulau Jawa berdasarkan beberapa literatur. Dalam satu wilayah seperti misalnya di daerah Pegunungan Serayu Utara bisa terdapat beberapa jenis gerakan tanah termasuk soil creep dimana kecepatan soil creep ini dapat berkisar antara $24 \mathrm{~cm}$ hingga $40 \mathrm{~cm}$ per tahun. Pawlik dan Samonil (2018) melakukan tinjauan pustaka dalam bentuk ulasan tentang soil creep. Teknik dendrochronology dianggapnya kurang memiliki tingkat keakuratan yang baik dan menyarankan agar ke depan dapat dilakukan penelitian lebih jauh tentang soil creep dengan teknik radiometri, laser scanning dan soil micromorphology.

Conte et al (2017) dari penelitiannya menunjukkan bahwa mobilitas gerakan tanah dapat diamati secara lebih sederhana. Pengamatan gerakan tanah yang sebelumnya adalah dengan melihat naiknya muka air tanah dan mengkorelasikannya dengan pergerakan tanah. Naiknya muka air tanah adalah akibat curah hujan yang meresap ke dalam tanah dan kemudian merubah kesetimbangan kondisi tanah di lereng. Dalam hal ini pengamatan gerakan tanah dapat dilakukan langsung dengan mengamati curah hujan sehingga mobilitas gerakan tanah dapat diprediksi langsung dengan melihat besar curah hujan yang terjadi. Cara ini lebih sederhana dibandingkan dengan dengan cara pengamatan muka air tanah. Prediksi pergerakan tanah dapat dilakukan dengan melihat curah hujan dan parameter masukan yang digunakan juga lebih sedikit.

Pada daerah yang luas, soil creep dapat dideteksi dan dimonitor dengan menggunakan citra satelit yang diambil dalam beberapa waktu dengan periode yang berturutan. Stumpf et al (2017) dalam pengamatannya menggunakan citra satelit dengan teknik multiple pairwise image correlation (MPIC) dapat mendeteksi dan memonitor rayapan tanah pada 169 lokasi di Pegunungan Alpen di Perancis Selatan. Korelasi yang positif ditemukan antara ukuran gerakan tanah dan kecepatannya demikian juga dengan kecepatan gerakan tanah terbesar dengan perubahan musim dalam hal ini hubungannya dengan curah hujan.

Dalam hal soil creep di Balekambang, penelitian lanjutan dapat dilakukan diantaranya dengan melakukan penelitian kondisi bawah permukaan dengan metode geolistrik dan hidrogeologi dengan pemboran. Namun demikian cara untuk mitigasi bencana gerakan tanah soil creep di Balekambang yang disarankan adalah dengan pengaturan peresapan air ke dalam tanah di daerah ini. Perlu diusahakan agar air permukaan tidak menggenang atau berada lama di permukaan khususnya pada waktu musim hujan. Seperti misalnya adanya sawah yang kurang sesuai dengan kondisi di daerah tersebut. Demikian pula vegetasi dari jenis tanaman berakar dalam dengan kemampuan menyerap air yang besar agar ditanam lebih banyak di daerah tersebut. Patok sederhana penanda gerakan tanah dapat dipasang di beberapa lokasi untuk memonitor gerakan tanah.

\section{KESIMPULAN}

Longsor yang terjadi di Balekambang merupakan jenis rayapan tanah atau soil creep. Jenis longsor di daerah ini adalah soil creep. Pergerakan yang lambat ini menunjukkan bahwa kestabilan lereng berada pada dekat batas instabilitas. Soil creep ini dikontrol oleh perlapisan batuan dimana lempung dan napal berfungsi sebagai bidang gelincir. Bidang perlapisan searah dengan arah longsor menunjukkan kontrol yang kuat dari litologi baik jenis maupun arah perlapisan untuk terjadinya soil creep. Curah hujan diperkirakan sebagai pemicu utama terjadinya soil creep. Faktor lain yang mungkin berpengaruh adalah perubahan lingkungan di sekitar daerah soil creep berupa bertambahnya bangunan, perubahan lahan hutan menjadi terbuka, penambangan batugamping dan perubahan iklim.

\section{DAFTAR PUSTAKA}

Chen, Chien-Yuan dan Huang, Wen-Lin 2013, Land Use Change and Landslide Characteristics Analysis for Community-based Disaster Mitigation, Environmental Monitoring and Assessment, Vol. 185, Issue 5, pp 41254139.

Conte, E., Donato, A. dan Troncone, A., 2017, A Simplified Method for Predicting RainfallInduced Mobility of Active Landslides, Landslides, Vol. 14, Issue 1, pp 35-45.

Hadmoko, D. S.; F. Lavigne; J. Sartohadi; P. Hadi dan Winaryo, 2010, Landslide Hazard and Risk Assessment and Their Application in Risk Management and Landuse Planning in Eastern Flank of Menoreh Mountains, Yogyakarta Province, Indonesia, Natural Hazards, Vol. 54, 
Issue 3, pp 623-642.

http://bandungbaratkab.go.id/halaman/geografis$\mathrm{kbb}$

http://vsi.esdm.go.id/gallery/index.php?/category/1 2

Hungr, O., Leroueil, S., Picarelli, 2014, The Varnes classification of landslide tipes, an update, Landslides, Volume 11, Issue 2, pp 167-194 https://doi.org/10.1007/s10346-013-0436-y

Kusumayudha, S. B. dan Ciptahening, A. N., 2016, Correlation between Tectonic Environment and Chracteristics of Mass Movement (Landslides): A Case Study from Java, Indonesia, Journal of Geological Resource and Engineering, Vol. 4, Number 2, pp. 4-17.

Pawlik, L. dan Samonil, P., 2018, Soil Creep: The Driving Factors, Evidence and Significance for Biogeomorphic and Pedogenic Domains and Systems - A Critical Literature Review, Earth Science Review, Vol. 178, Maret 2018, pp 257 -278 .

Petley, David, 2012, Global Patterns of Loss of Life from Landslides, Geology, Vol. 40 No. 10, pp 927-930.

PVMBG, 2016, Laporan Singkat Bencana Gerakan Tanah Kecamatan Cipatat, Kabupaten Bandung Barat Provinsi Jawa Barat http://www.vsi.esdm.go.id/ index.php/gerakantanah/kejadian-gerakan-tanah/1377-laporansingkat-bencana-gerakan-tanah-kec-cipatatkab-bandung-barat-provinsi-jawa-barat

Sabir, M. A., Umar, M., Farooq, M., Faridullah, F., 2016, Computing Soil Creep Velocity Using Dendrochronology, Bulletin of Engineering Geology and the Environment, Vol. 75, Issue 4, pp 1761-1768.

Sadarviana, V., Abidin H. Z., Kahar, J., Santoso, D; 2010, Karakteristik, Tipe Dan Bidang Gelincir Pada Zona Longsor Ciloto, Jawa Barat Berdasarkan Estimasi Metode Geodetik, Jurnal Geologi dan Sumberdaya Mineral, Vol. 20, No. 2, 117 - 120.

Sarah, D. dan M. R. Daryono, 2012, Engineering Geological Investigation of Slow Moving Landslide in Jahiyang Village, Salawu, Tasikmalaya Regency, (Investigasi Geologi Teknik pada Gerakan Tanah Lambat di Desa Jahiyang, Salawu, Kabupaten Tasikmalaya), Indonesian Journal of Geology, Vol. 7 No. 1 March 2012: 27-38.
Stumpf, A., Maleta, J. P., dan Delacourt, C., 2017, Correlation of Satellite Image Time-Series for the Detection and Monitoring of Slow-Moving Landslides, Remote Sensing of Environment, Vol. 189, pp 40-55.

Sudjatmiko, 1972, Peta Geologi Lembar Cianjur, Jawa, Pusat Penelitian Dan Pengembangan Geologi.

Varnes, D. J. 1978. Slope Movement Types And Processes. In: Special Report 176: Landslides: Analysis and Control (Eds: Schuster, R. L. \& Krizek, R. J.). Transportation and Road Research Board, National Academy of Science, Washington D. C., Pages 11-33. 